\title{
Model Dan Simulasi Prototype Rangkaian Digital Konversi Gerbang $A N D$, OR, NOT Menjadi Gerbang NAND Dan NOR
}

\author{
Helmi Fauzi Siregar ${ }^{1}$, Muhammad Dedi Irawan ${ }^{2}$ \\ 1,2 Program Studi Teknik Informatika, Universitas Asahan, Jl. Jend. Ahmad Yani Kisaran 21244, Sumatera Utara, Telp : (0623) 347222
}

\section{KEYWORDS \\ Gerbang AND, OR, NOT, Rangkaian Multilevel, Gerbang NAND dan NOR, Prototype}

\section{CORRESPONDENCE}

Phone: 085362553530

E-mail: fauzi.helmi.hf@gmail.com

\section{PENDAHULUAN}

Rangkaian digital adalah matakuliah yang ada di setiap perguruan tinggi baik swasta maupun negeri. Pada rangkaian digital dipelajari tentang karakteristik Gerbang Logika. Dimana Gerbang Logika itu sendiri terdiri dari tujuh bagian, yaitu AND, OR, NOT, NAND, NOR, Ex-OR, dan Ex-NOR. Pada gerbang logika ada dua gerbang yang dikenal gerbang Multilevel yaitu gerbang NAND dan NOR. Gerbang Multilevel inilah yang dapat dijadikan sebagai gerbang untuk melakukan konversi Rangkaian kombinasi AND, OR, NOT menjadi Rangkaian Gerbang NAND dan NOR. Dimana pemakaian Gerbang NAND dan NOR dalam sebuah Rangkaian Digital adalah untuk dapat mengoptimalkan pemakaian seluruh gerbang yang terdapat dalam sebuah IC, sehingga menghemat biaya.

Konversi Rangkaian kombinasi gerbang $A N D$, OR, NOT ke Rangkaian Gerbang NAND, dan NOR berdasarkan referensireferensi yang didapat ada dua cara, yaitu Melalui penyelesaian persamaan logika/boolean dan langsung dari gambar padanan..

Penulis ingin membahas pada penelitian ini, yaitu pada https://doi.org/10.30743/xxxxx rangkaian kombinasi gerbang $A N D, \quad O R, \quad N O T$ dapat merubah rangkaian kombinasi tersebut menjadi Rangkaian NAND dan NOR saja. Dimana rangkaian kombinasi nanti akan diberikan input 3(tiga) input bit dan mengahasilkan output yang sama. Kemudian Rangkaian kombinasi tersebut akan dikomversikan menjadi Rangkaian Gerbang NAND dan NOR saja yang akan menghasilkan output yang sama.

Penulis ingin menyajikan pada penelitian ini dalam bentuk Prototype untuk menjadi alat yang dapat membantu memahami konversi rangkaian kombinasi tersebut ke dalam Rangkaian Gerbang NAND dan NOR saja. Kemudian yang ingin penulis ungkap pada penelitian ini adalah bahwa Rangkaian kombinasi tersebut dapat dirubah dengan cepat dengan hanya Rangkaian Gerbang NAND dan NOR saja.

\section{Rumusan Masalah}

Rumusan masalah dari penelitian ini adalah sebagai berikut :

1. Bagaimana Rangkaian kombinasi AND, OR, NOT dikonversikan dengan menggunakan Gerbang NAND dan NOR?

2. Bagaimana hasil output antara rangkaian kombinasi $A N D$, $O R$, NOT setelah dikonversi dengan rangkaian NAND dan NOR? 


\section{Batasan Masalah}

Batasan masalah yang digunakan dalam penelitian ini adalah :

1. Penelitian ini hanya membahas konversi Rangkaian kombinasi AND, OR, NOT dengan menggunakan Rangkaian Gerbang NAND dan NOR saja.

2. Hasil konversi akan ditampilkan pada LCD

3. Konversi Rangkaian kombinasi dilakukan dengan menggunakan Prototype Rangkaian Gerbang NAND dan NOR.

\section{Tujuan Penelitian}

1. Membuat dan menerapkan model Prototype untuk alat praktek di dalam memahami proses konversi Rangkaian kombinasi Gerbang AND, OR, NOT.

2. Mengevaluasi rangkaian kombinasi dengan rangkaian yang menggunakan gerbang logika NAND dan NOR.

3. Membuat alat simulasi berupa Prototype di dalam mempraktekkan proses konversi Rangkaian kombinasi $A N D, O R, N O T$ dengan Rangkaian Gerbang NAND dan NOR.

\section{Manfaat Penelitian}

Adapun manfaat dari penelitian ini adalah :

1. Dapat memberikan hasil secara cepat, tepat, dan akurat dalam melakukan konversi Rangkaian kombinasi $A N D, O R, N O T$ dengan Rangakaian yang menggunakan Gerbang NAND dan NOR.

2. Dapat membantu mahasiswa dikalangan perguruan tinggi swasta maupun negeri dalam memahami proses konversi Rangkaian kombinasi Gerbang NAND dan NOR yang dilakukan.

\section{METODE}

Metode Penelitian yang digunakan adalah :

1. Metode Deskriptif

Pada metode ini data yang ada dikumpulkan, disusun, dikelompokkan, dianalisa sehingga diperoleh beberapa gambaran yang jelas pada masalah penelitian tersebut.

2. Metode Komperatif

Pada metode ini penganalisaan di lakukan dengan cara membandingkan teori dan praktek sehingga diperoleh gambaran yang jelas tentang persamaan dan perbedaan diantara keduanya.

Adapun kerangka kerja dari penelitian ini dapat dilihat pada gambar 1 berikut:

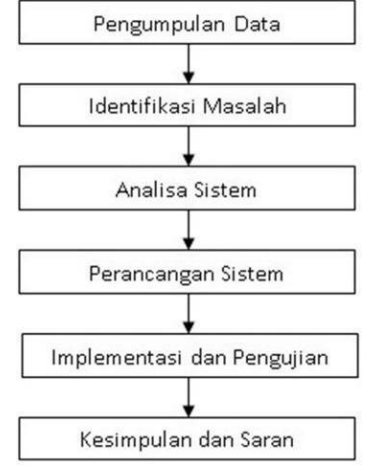

Gambar 1. Kerangka kerja penelitian

Untuk tahapan perancangan ini ada beberapa tahapan yang penulis lakukan :

1. Penggambaran model rancangan dengan UML (Unified Modelling Language)

2. Penggambaran simulasi dinamis dari prototype yang dibuat

3. Mekanisme Implementasi dan Pengujian dari prototype yang dibuat.

\section{HASIL DAN DISKUSI}

Analisa sistem yang didapatkan dengan menggunakan metode deskriptif adalah perancangan rangkaian gerbang logika yang menggunakan power supply sebagai input (masukan) tegangan ke PCB rangkaian dengan IC 7400 dan 7402 sebagai rangkaian gerbang logika NAND dan NOR dengan terhubung pada saklar togle untuk logika input 0 (Low) dan 1 (high) dan output keluaran yang dihasilkan adalah dengan lampu LED hidup untuk logika 1 (High) dan lampu LED mati untuk logika 0 (Low).

1. Arsitektur Sistem Rangkaian Gerbang Logika

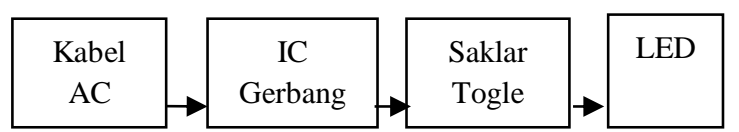

Gambar 2. Asitektur Sistem Rangkaian Gerbang Logika

2. Use Case Diagram

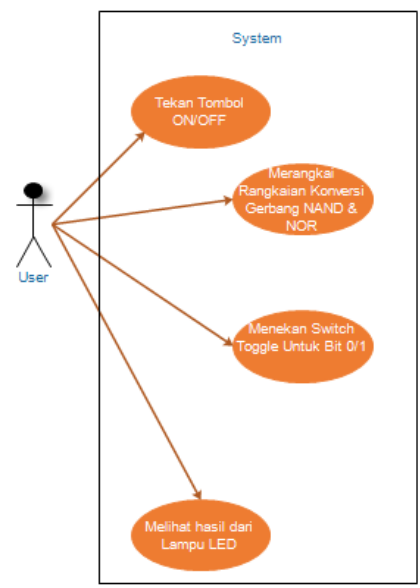

Gambar 3. Use Case Diagram Sistem Digital Trainer

Keterangan : User menghidupkan Digital Trainer dengan menekan tombol ON/OFF, kemudian merangkai rangkaian 
konversi Gerbang NAND dan NOR. Setelah itu menekan Switch Toggle untuk memberikan Bit 0/1 dan melihat hasilnya apakah sudah sesuai dengan hasil dari rangkaian asal.

\section{State Machine Diagram}

State Machine Diagram merupakan gambaran perlakuan terhadap sistem Digital Trainer yang dibuat. Dimana User melakukan kegiatan untuk merangkai rangkaian konversi dengan Gerbang NAND dan NOR dari Rangkaian Asal yang di Uji Coba. Berikut ini gambar 4. State Machine Diagram aliran behavior pada sistem.

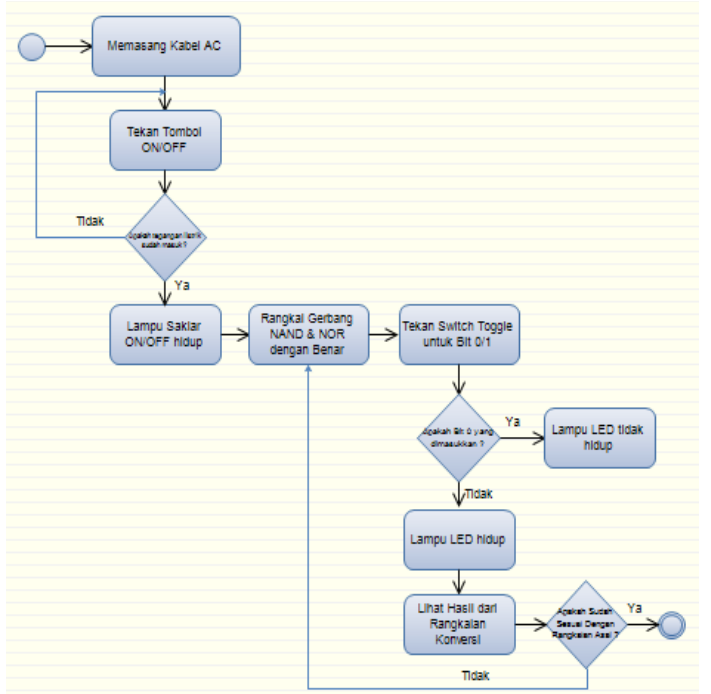

Gambar 4. State Machine Diagram Sistem Digital Trainer

\section{Component Diagram}

Component diagram merepresentasikan paket fisik dari Digital Trainer. Component diagram juga menunjukkan interface yang digunakan untuk komunikasi antar komponen. Berikut ini adalah gambar 5. component diagram dari sistem yang dibangun.

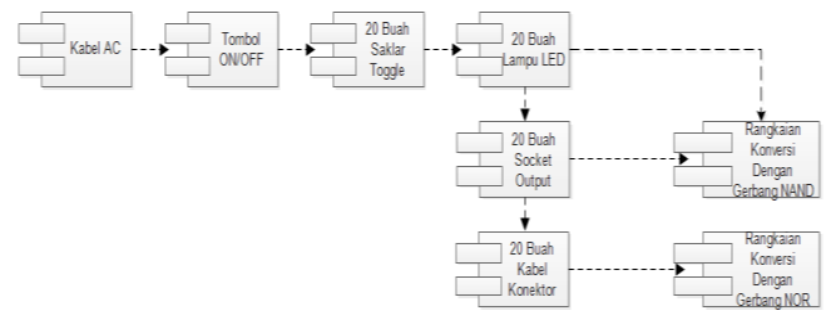

Gambar 5. Component Diagram Sistem Digital Trainer

5. Rangkaian Asal

Berikut ini adalah gambar dari Rangkaian Asal yang akan dikonversikan :

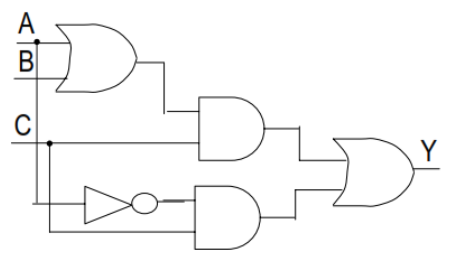

Gambar 6. Rangkaian Asal
Dari gambar 6. Apabila diinputkan dengan 3-input Bilangan Biner adalah sebagai berikut :

Tabel Kebenaran 3-Input

\begin{tabular}{|c|c|c|c|}
\hline \multicolumn{3}{|c|}{ INPUT } & OUTPUT \\
\hline $\mathrm{A}$ & $\mathrm{B}$ & $\mathrm{C}$ & $Y$ \\
\hline 0 & 0 & 0 & 0 \\
\hline 0 & 0 & 1 & 1 \\
\hline 0 & 1 & 0 & 0 \\
\hline 0 & 1 & 1 & 1 \\
\hline 1 & 0 & 0 & 0 \\
\hline 1 & 0 & 1 & 1 \\
\hline 1 & 1 & 0 & 0 \\
\hline 1 & 1 & 1 & 1 \\
\hline
\end{tabular}

6. Rangkaian Konversi

6.1 Rangkaian Konversi Dengan Gerbang NAND

Berikut ini adalah gambar rangkaian konversi dengan gerbang NAND :

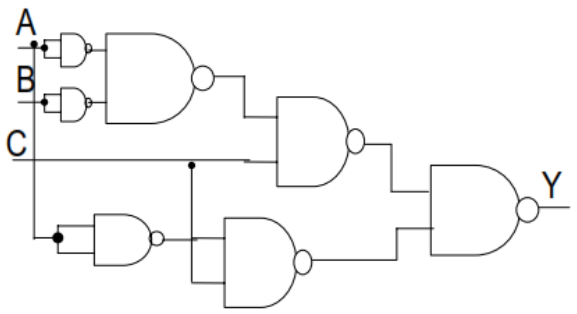

Gambar 7. Rangkaian Konversi Dengan Gerbang NAND

6.2 Rangkaian Konversi Dengan Gerbang NOR

Berikut ini adalah gambar rangkaian konversi dengan gerbang NOR :

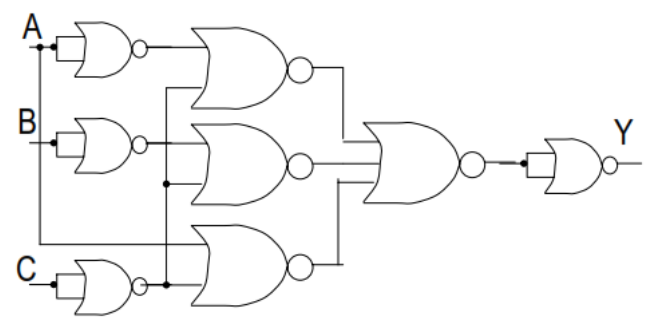

Gambar 8. Rangkaian Konversi Dengan Gerbang NOR

Dari gambar rangkaian konversi diatas didapatkan dari penyederhanaan dengan menggunakan Tabel Padanan Gambar (Tocci R.J., 2007) berikut ini :

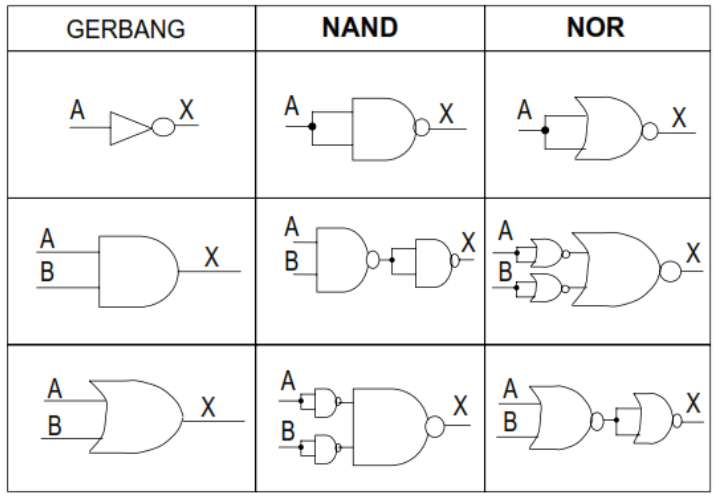

Maka tabel kebenaran dari Rangkaian Konversi diatas adalah sama hasil outputnya dengan tabel kebenaran Rangkaian Asal. 
Tabel Kebenaran 3-Input

\begin{tabular}{|c|c|c|c|}
\hline \multicolumn{3}{|c|}{ INPUT } & OUTPUT \\
\cline { 1 - 2 } $\mathrm{A}$ & $\mathrm{B}$ & $\mathrm{C}$ & $Y$ \\
\hline 0 & 0 & 0 & 0 \\
\hline 0 & 0 & 1 & 1 \\
\hline 0 & 1 & 0 & 0 \\
\hline 0 & 1 & 1 & 1 \\
\hline 1 & 0 & 0 & 0 \\
\hline 1 & 0 & 1 & 1 \\
\hline 1 & 1 & 0 & 0 \\
\hline 1 & 1 & 1 & 1 \\
\hline
\end{tabular}

\section{IMPLEMENTASI DAN PEMBAHASAN}

\subsection{Tahapan Implementasi}

Berikut ini adalah implementasi Prototype Digital Trainer yang dibuat dan dilakukan pada Rangkaian Asal ketika dikonversikan menggunakan Rangkaian Gerbang NAND dan NOR :

1. Hasil Konversi Dari Rangkaian Gerbang NAND

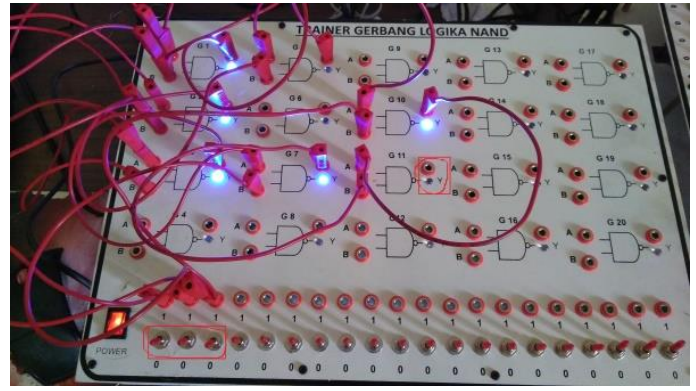

Gambar 9. Prototype Digital Trainer Dengan Input 0,0,0.

Dari Gambar 9 diatas, terlihat prototype digital trainer dengan inputan 0,0,0 menghasilkan output $\mathrm{Y}=0$.

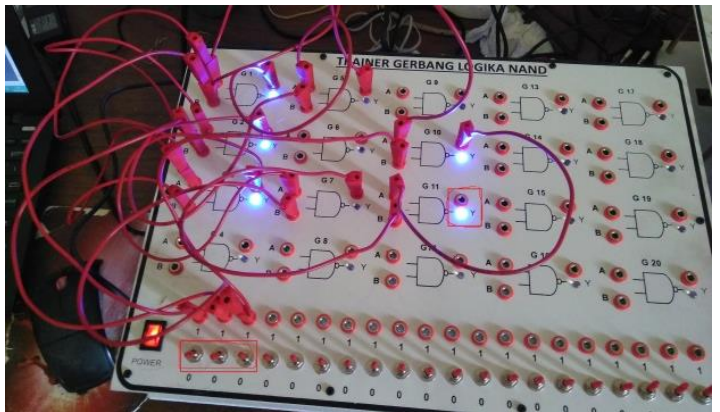

Gambar 10. Prototype Digital Trainer Dengan Input 0,0,1.

Dari Gambar 10 diatas, terlihat prototype digital trainer dengan inputan $0,0,1$ menghasilkan output $\mathrm{Y}=1$.

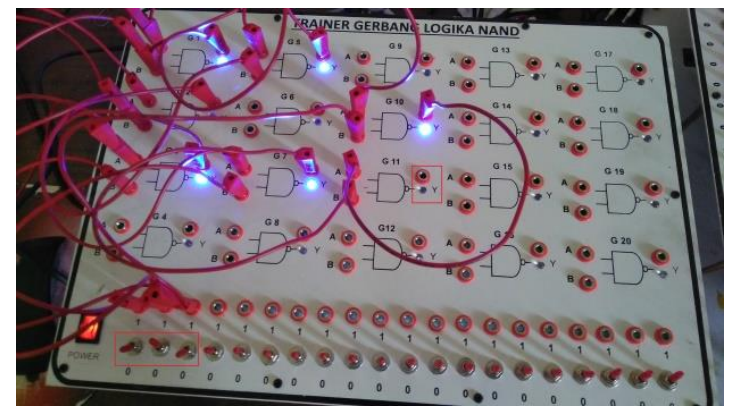

Gambar 11. Prototype Digital Trainer Dengan Input 0,1,0.
Dari Gambar 11 diatas, terlihat prototype digital trainer dengan inputan $0,1,0$ menghasilkan output $\mathrm{Y}=0$.

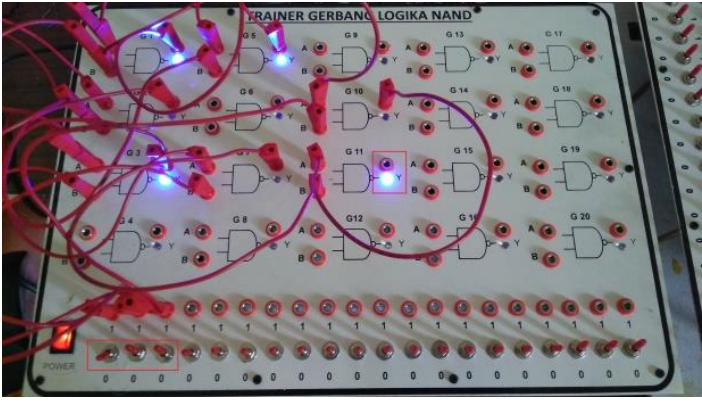

Gambar 12. Prototype Digital Trainer Dengan Input 0,1,1.

Dari Gambar 12 diatas, terlihat prototype digital trainer dengan inputan $0,1,1$ menghasilkan output $\mathrm{Y}=1$.

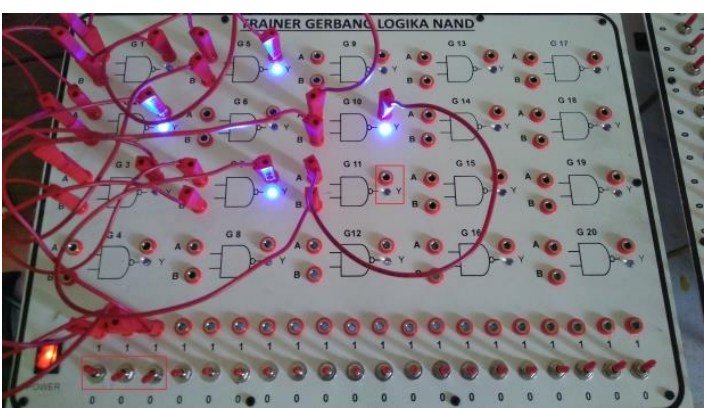

Gambar 13. Prototype Digital Trainer Dengan Input 1,0,0.

Dari Gambar 13 diatas, terlihat prototype digital trainer dengan inputan 1,0,0 menghasilkan output $\mathrm{Y}=0$.

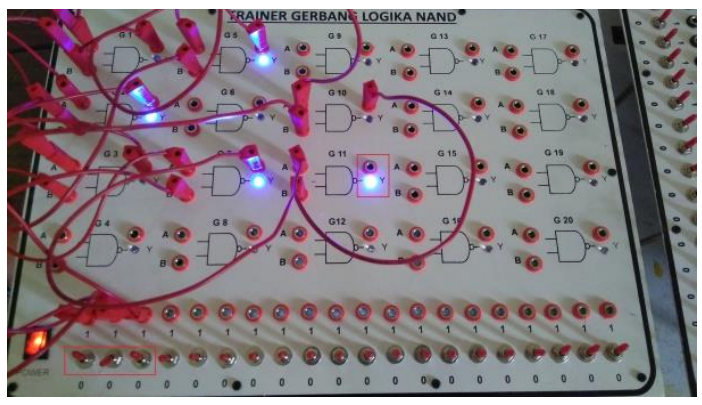

Gambar 14. Prototype Digital Trainer Dengan Input 1,0,1.

Dari Gambar 14 diatas, terlihat prototype digital trainer dengan inputan 1,0,1 menghasilkan output $\mathrm{Y}=1$.

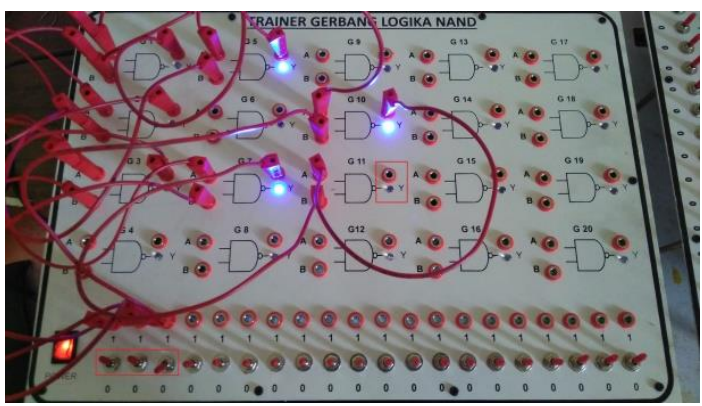

Gambar 15. Prototype Digital Trainer Dengan Input 1,1,0.

Dari Gambar 15 diatas, terlihat prototype digital trainer dengan inputan 1,1,0 menghasilkan output $\mathrm{Y}=1$. 


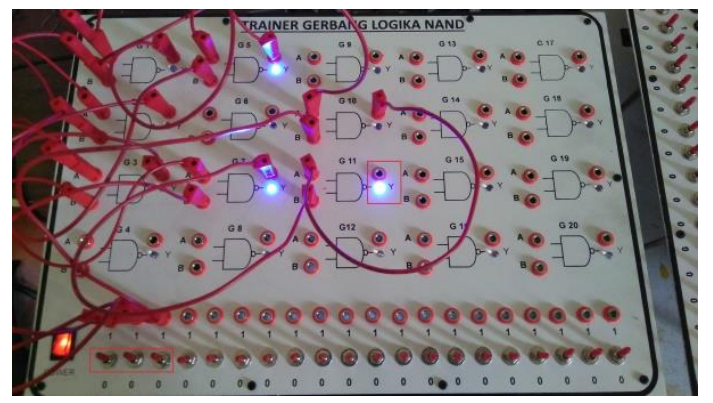

Gambar 16. Prototype Digital Trainer Dengan Input 1,1,1.

Dari Gambar 16 diatas, terlihat prototype digital trainer dengan inputan 1,1,1 menghasilkan output $\mathrm{Y}=1$.

2. Hasil Konversi Dari Rangkaian Gerbang NOR

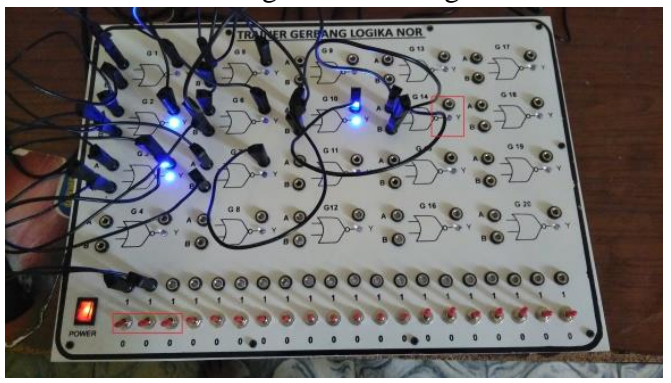

Gambar 17. Prototype Digital Trainer Dengan Input 0,0,0.

Dari Gambar 17 diatas, terlihat prototype digital trainer dengan inputan 0,0,0 menghasilkan output $\mathrm{Y}=0$.

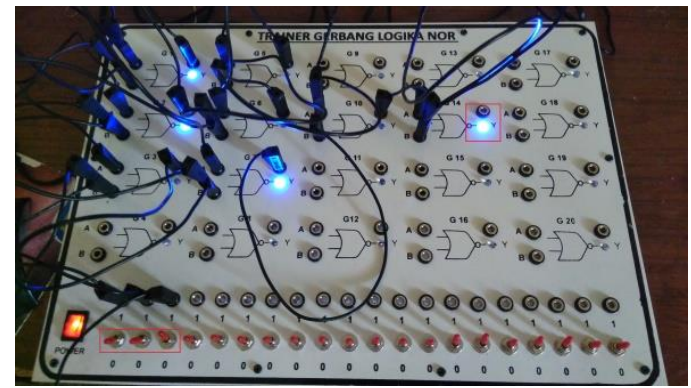

Gambar 18. Prototype Digital Trainer Dengan Input 0,0,1.

Dari Gambar 18 diatas, terlihat prototype digital trainer dengan inputan 0,0,1 menghasilkan output $\mathrm{Y}=1$.

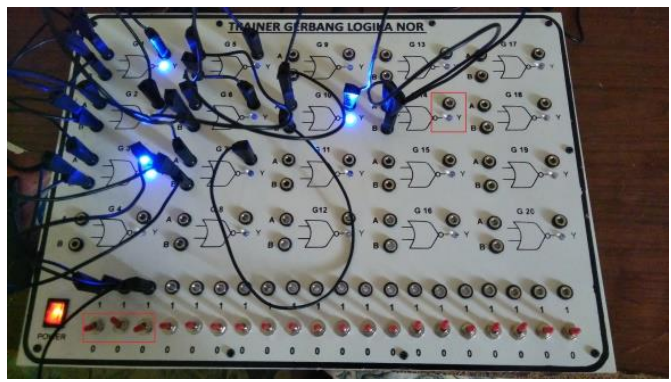

Gambar 19. Prototype Digital Trainer Dengan Input 0,1,0.

Dari Gambar 19 diatas, terlihat prototype digital trainer dengan inputan $0,1,0$ menghasilkan output $\mathrm{Y}=0$.

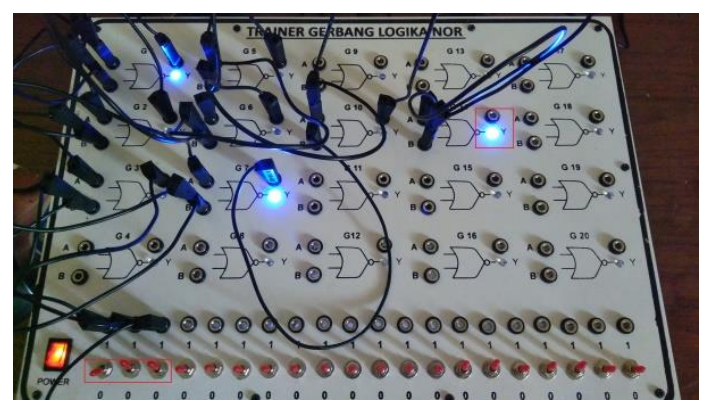

Gambar 20. Prototype Digital Trainer Dengan Input 0,1,1.

Dari Gambar 20 diatas, terlihat prototype digital trainer dengan inputan $0,1,1$ menghasilkan output $\mathrm{Y}=1$.

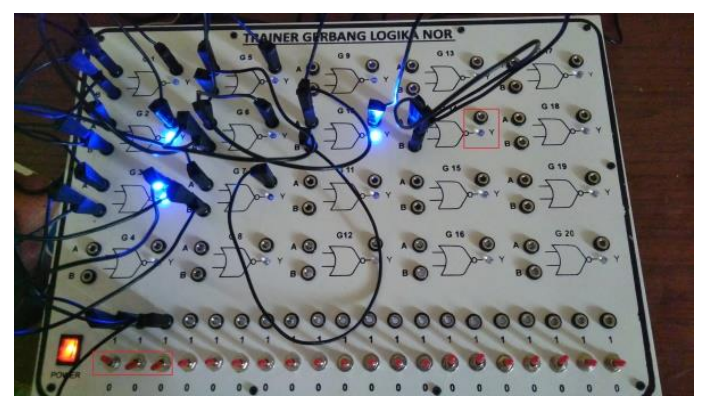

Gambar 21. Prototype Digital Trainer Dengan Input 1,0,0.

Dari Gambar 21 diatas, terlihat prototype digital trainer dengan inputan 1,0,0 menghasilkan output $\mathrm{Y}=0$.

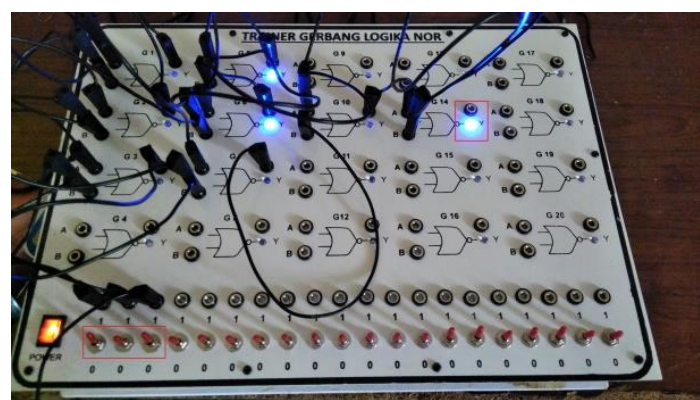

Gambar 22. Prototype Digital Trainer Dengan Input 1,0,1.

Dari Gambar 22 diatas, terlihat prototype digital trainer dengan inputan 1,0,1 menghasilkan output $\mathrm{Y}=1$.

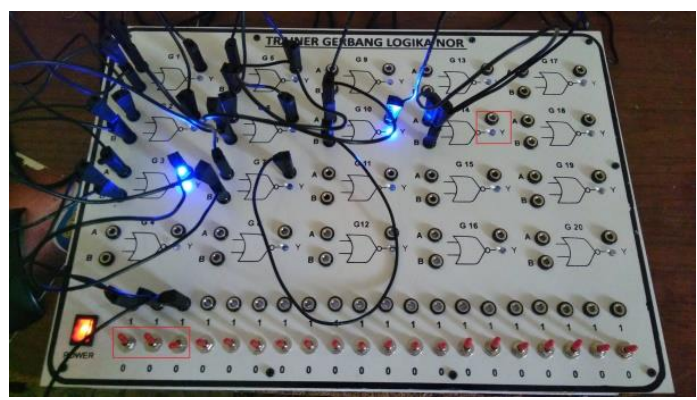

Gambar 23. Prototype Digital Trainer Dengan Input 1,1,0.

Dari Gambar 23 diatas, terlihat prototype digital trainer dengan inputan 1,1,0 menghasilkan output $\mathrm{Y}=1$. 


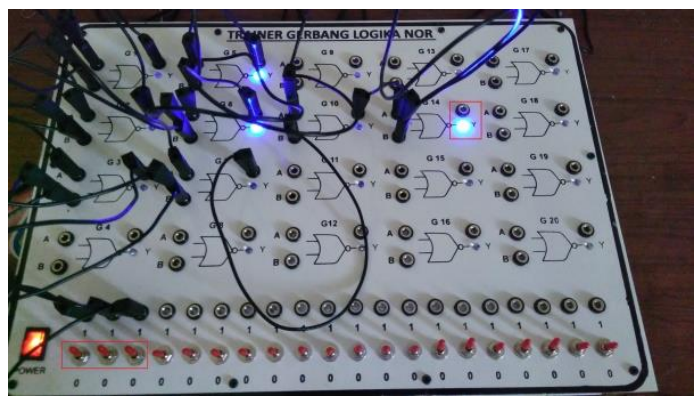

Gambar 24. Prototype Digital Trainer Dengan Input 1,1,1.

Dari Gambar 24 diatas, terlihat prototype digital trainer dengan inputan 1,1,1 menghasilkan output $\mathrm{Y}=1$.

\section{KESIMPULAN}

Prototype yang dihasilkan dari penelitian ini dapat dipergunakan sebagai alat simulasi pembelajaran sistem digital dalam memahami rangkaian multilevel NAND dan NOR.

Prototype yang dihasilkan dapat memberikan hasil output yang sama dari rangkaian asal yang dibentuk dari rangkaian Gerbang AND, OR, NOT dengan rangkaian konversi yang dibentuk dari Rangkaian Gerbang NAND dan NOR.

Prototype yang dibuat ini dapat memberikan pengetahuan kepada mahasiswa bahwa membuat rangkaian multilevel tersebut dapat dengan mudah diimplementasikan.

\section{UCAPAN TERIMA KASIH}

Penulis mengucapkan banyak terima kasih Kepada Direktur Riset dan Pengabdian Masyarakat (DRPM) Kementerian Riset, Teknologi dan Pendidikan Tinggi atas pembiayaan Penelitian Dosen Pemula (PDP) sebesar Rp. 19.647.000,- dengan SK. Nomor T/199/L1.3.1/PT.01.03/2019.

\section{REFERENSI}

[1]. Mathius Nugroho. 2015. Rangkaian Adder Dengan Seven Segment. Skripsi. Fakultas Teknologi Industri Universitas Internasional, Batam

[2]. Muhammad Irmansyah. 2009. Gerbang Logika Berbasis Programmable Logic Device (PLD). Elektron. Vol. 1, No. 1. 75-81.

[3]. Kurniawan, Fredly.2005. Jurnal Sistem Digital Konsep Dam Aplikasi Volume 3. Yogyakarta: Gava Media

[4]. Abdul Jabar. (2011). "Pemodelan dan Simulasi Dinamis Pendeteksi Dini Gempa Pada Gedung “. Universitas Putra Indonesia YPTK Padang : Tesis M.Kom.

[5]. Law, A. and Kelton W., 2000, "Simulation Modelling and Analysis", $3^{\text {rd }}$, Mc Graw-Hill.

[6]. Tocci R.J., et al. (2007). "Digital Systems Principles And Aplications”, $10^{\text {ed }}$, Pearson Prentice Hall.
[7]. Martin Fowler. (2005). "UML Distilled." $3^{\text {th }}$. Ed. A Brief Guide to the Standard Object Modelling Language : Andi. 151-160.

\section{BIOGRAPI PENULIS}

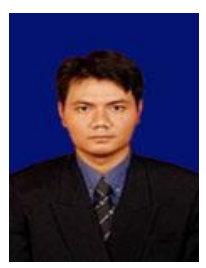

Helmi Fauzi Siregar

Bekerja sebagai Dosen di Perguruan Tinggi Swasta Universitas Asahan dari Tahun 2016 sampai dengan sekarang. Telah memenangkan PDP Hibah DIKTI sebanyak dua kali dan banyak membuat artikel-artikel ilmiah yang dimuat di dalam jurnal Nasional.

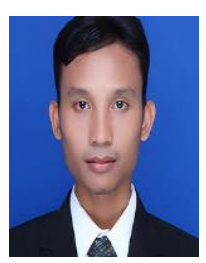

\section{Muhammad Dedi Irawan}

Bekerja sebagai Dosen di Perguruan Tinggi Swasta Universitas Asahan dari Tahun 2016 sampai dengan sekarang. Telah memenangkan PDP Hibah DIKTI sebanyak 1 kali dan membuat artikel-artikel ilmiah yang dimuat di dalam jurnal Nasional dan International. 